\title{
PENGARUH KUALITAS PRODUK DAN KUALITAS PELAYANAN TERHADAP KEPUASAN KONSUMEN DI SUSHI DEN BANDUNG
}

\section{EFFECT OF PRODUCT QUALITY AND SERVICE QUALITY ON CUSTOMER SATISFACTION AT SUSHI DEN BANDUNG}

\author{
Devi Anggraeni, Agus Sudono, Dewi Turgarini \\ Program Studi Manajemen Industri Katering \\ Fakultas Pendidikan Ilmu Pengetahuan Sosial \\ Universitas Pendidikan Indonesia \\ devianggra3009@gmail.com
}

\begin{abstract}
Customer satisfaction is the most important thing in the catering business. Customer satisfaction affect the profit earned by entrepreneur food. Things that can affect customer satisfaction among them is the quality of product and quality of services provided by the food producers. One way to determine customer satisfaction is to compare the expectation and the reality perceived by the customer.

Research method used in this research is descriptive verification method. The number of samples in this research were 100 consumers, data collection is done by spreading the questionnaire and documentary study. Model analysis of the data used is multiple linear regression using SPSS 22 for windows. The results showed that the Product Quality and Service Quality has significant impact on customer satisfaction. Results of calculations using multiple linear regression analysis obtain the equation $Y=3,291+0,059 X_{1}+0,152 X_{2}$ it means an increase by 1 unit Product Quality, the Consumer Satisfaction Sushi Den Bandung will increase by 0.059 and any increase Quality of Service by 1 unit, the Consumer Satisfaction Sushi Den Bandung will also rise by 0.152. Food producers should further improve the quality of product quality and service quality by determining and implementing the Standard Operational Procedure properly in order to provide a positive impact for food company.

Keywords: Product Quality, Service Quality and Customer Satisfaction
\end{abstract}

\begin{abstract}
ABSTRAK
Kepuasan Konsumen adalah hal terpenting dalam usaha jasa boga. Kepuasan konsumen berpengaruh kepada keuntungan yang diperoleh oleh pengusaha makanan. Hal-hal yang dapat mempengaruhi kepuasan konsumen diantaranya adalah kualitas produk dan kualitas pelayanan yang diberikan oleh pengusaha makanan. Salah satu cara untuk mengetahui kepuasan konsumen adalah dengan membandingkan harapan dan kenyataan yang dirasakan oleh konsumen tersebut.

Metode penelitian yang digunakan adalah metode deskriptif verifikatif. Jumlah sampel pada penelitian ini sebanyak 100 konsumen, pengumpulan data dilakukan dengan cara menyebar kuesioner dan studi dokumentasi. Model analisis data yang digunakan adalah regresi linier berganda dengan menggunakan bantuan
\end{abstract}


software SPSS 22 for windows. Hasil penelitian menunjukkan bahwa Kualitas Produk dan Kualitas Pelayanan memberikan pengaruh yang signifikan terhadap Kepuasan Konsumen. Hasil perhitungan menggunakan analisis Regresi Linier Berganda mendapatkan persamaan $\mathrm{Y}=3,291+0,059 \mathrm{X}_{1}+0,152 \mathrm{X}_{2}$ maknanya peningkatan Kualitas Produk sebesar 1 satuan maka Kepuasan Konsumen Sushi Den Bandung akan meningkat sebesar 0,059 dan setiap peningkatan Kualitas Pelayanan sebesar 1 satuan maka Kepuasan Konsumen Sushi Den Bandung akan meningkat pula sebesar 0,152. Pengusaha makanan sebaiknya lebih meningkatkan mutu kualitas produk dan kualitas pelayanan dengan cara menetapkan dan melaksanakan Standard Operational Procedure dengan baik dan benar agar memberikan dampak yang positif bagi perusahaan.

Kata Kunci : Kualitas Produk, Kualitas Pelayanan, dan Kepuasan Konsumen

\section{PENDAHULUAN}

Menurut Undang-Undang Republik Indonesia nomor 10 tahun 2009 pariwisata adalah berbagai macam kegiatan wisata yang didukung berbagai fasilitas serta layanan yang disediakan masyarakat, pengusaha, pemerintah dan pemerintah daerah. Daerah tujuan wisata atau destinasi pariwisata adalah kawasan geografis yang berada dalam satu atau lebih wilayah administrasi yang didalamnya terdapat daya tarik wisata. Indonesia merupakan negara yang menjadi salah satu destinasi pariwisata favorit bagi wisatawan.

Pariwisata di Indonesia memegang peranan penting dalam sektor perekonomian. Pada tahun 2013 Indonesia berada di peringkat 70 dalam daya saing pariwisata global menurut World Economic Forum (WEF) setelah sebelumnya mengalami kenaikan 4 peringkat dari peringkat 74 pada tahun 2011.

Salah satu daerah tujuan wisata yang ada di Indonesia selain Bali adalah Bandung. Selain menawarkan pemandangan yang indah para wisatawan bisa berbelanja dan dimanjakan dengan aneka kuliner yang ada di Bandung. Kota Bandung terdapat berbagai macam restoran yang menyajikan beraneka macam makanan dari mulai makanan khas Indonesia sampai makanan-makanan khas Negara lain, diantaranya makanan khas Negara Italia, Korea dan Jepang. Salah satu restoran yang menyediakan makanan Jepang adalah Restoran Sushi Den.

Sushi Den merupakan salah satu restoran yang menyediakan beraneka ragam makanan khas Jepang seperti okonomiyaki, ramen dan tentunya sushi. Sushi Den terletak di jalan Hariang Banga nomor 8 Bandung. Restoran yang berdiri sejak tahun 2009 ini menyediakan beraneka ragam sushi dari mulai sushi yang mentah sampai sushi yang matang. Sushi Den bukan satu-satunya restoran yang menyediakan sushi di kota Bandung, ada beberapa perusahaan sejenis yang bermunculan. Banyaknya usaha sejenis yang terus bermunculan maka pengusaha makanan seharusnya mulai memperhatikan tingkat kepuasan para konsumennya. Menurut Kotler dan Keller (2010 hlm 138), secara umum kepuasan (satisfaction) adalah perasaan senang atau kecewa seseorang yang timbul karena membandingkan kinerja yang dipersepsikan produk (atau hasil) terhadap ekspektasi mereka.

Beberapa hal yang mempengaruhi kepuasan konsumen selain dari produk

yang ditawarkan adalah service quality atau kualitas pelayanan. Selain 
memperhatikan produk yang akan dibeli, konsumen juga memperhatikan pelayanan yang akan diterima. Kepuasan dan ketidakpuasan konsumen akan berpengaruh pada pola perilaku selanjutnya, apabila konsumen merasa puas maka dia akan menunjukkan besar kemungkinan untuk kembali datang dan memberikan referensi yang baik kepada orang lain. Sebaliknya, apabila konsumen merasa tidak puas maka pelanggan tidak akan kembali datang dan memberikan referensi yang negatif kepada orang lain. Sebuah restoran harus memiliki cara untuk menarik minat konsumen untuk datang dan melakukan pembelian di restoran tersebut, ini berlaku pula untuk restoran Sushi Den. Jika restoran ini tidak bisa menarik minat konsumen untuk berkunjung dan tidak bisa memberikan kepuasan kepada konsumen, maka konsumen akan memberikan tanggapan terhadap ketidakpuasannya tersebut.

Menurut Marsum (2005 hlm 159) dan Bartono (2005 hlm 43), dimensi atau variabel yang digunakan untuk menentukan kualitas produk adalah Visual appeal (daya penarik lewat ketajaman mata), Aromatic appeal (daya penarik lewat bau harum), Flavor (rasa atau bau), Porsi yang baik dan tepat dengan standar penyajian, dan ketepatan waktu atau timing yang tepat dalam menyajikan.

Sedangkan kualitas pelayanan dijelaskan oleh Lovelock (2010 hlm 154) yaitu Tangibles (penampilan fasilitas fisik, peralatan, personil dan materi komunikasi), Empathy (akses, komunikasi dan pemahaman pelanggan), Reliability (keandalan atau kemampuan untuk melakukan pelayanan yang dijanjikan, dapat diandalkan dan akurat), Responsiveness (kecepatan dan kesediaan untuk membantu pelanggan), serta Assurance (kredibilitas, keamanan, kompetensi dan kesopanan).

Tujuan dilakukannya penelitian ini adalah untuk mengetahui kualitas produk di Sushi Den Bandung, untuk mengetahui kualitas pelayanan di Sushi Den Bandung, untuk mengetahui kepuasan konsumen di Sushi Den Bandung, dan untuk mengetahui pengaruh kualitas produk dan kualitas pelayanan terhadap kepuasan konsumen di Sushi Den Bandung.

\section{METODE PENELITIAN}

Metode penelitian yang digunakan dalam penelitian ini adalah Penelitian Deskriptif dan Penelitian Verifikatif. Adapun operasional variabelnya adalah: Marsum (2005) dan Bartono (2005) meyatakan dimensi kualitas produk yaitu, Aromatic appeal (Aroma atau daya penarik lewat bau harum), Timing (Ketepatan waktu yang tepat dalam menyajikan), Flavor (Rasa dari makanan yang disajikan), Portion (Porsi yang baik dan tepat sesuai dengan standar penyajian), dan Visual appeal (Daya tarik dari tampilan makanan yang disajikan). Kualitas yang dirasakan dari pelayanan adalah hasil dari suatu proses evaluasi dimana pelanggan membandingkan persepsi mereka terhadap pelayanan dan hasilnya, dengan apa yang mereka harapkan (Gronroos dalam Lovelock et. al. 2010: 154). Adapun dimensi dari kualitas pelayanan yang digunakan adalah: Tangibles (Kerapihan penampilan pegawai), Empathy (Kepekaan pegawai terhadap hal yang dibutuhkan konsumen), Reliability (Ketepatan pegawai dalam melayani konsumen), Responsiveness (Ketanggapan atau ketelitian pegawai pada saat melayani konsumen), dan Assurance (Keramahan dan kesopanan pegawai pada saat memberikan pelayanan). 
Menurut Sugiyono (2012 hlm 61), populasi diartikan sebagai wilayah generalisasi yang terdiri atas objek atau subjek yang mempunyai kualitas dan karakteristik tertentu yang ditetapkan oleh peneliti untuk dipelajari dan kemudian ditarik kesimpulannya. Adapun yang menjadi populasi dalam penelitian ini adalah konsumen yang telah menggunakan dan merasakan produk dan pelayanan dari Sushi Den Bandung.

Teknik analisis data yang digunakan adalah Analisis Deskriptif. Setelah pengumpulan data dari kuisioner terkumpul, mengolah dan mendeskripsikan data, sehingga dapat dilihat apakah terdapat pengaruh dan hubungan antar variabel kualitas produk dan kualitas pelayanan. Untuk mengolah data tersebut tahapan prosedur yang dilakukan adalah sebagai berikut: Pengambilan data, wawancara kepada karyawan dan penyebaran kuisioner kepada konsumen yang menjadi responden, Menyusun data dan mengolah data hasil kuisioner, Rekapitulasi nilai angket variabel kualitas produk (X1), kualitas pelayanan (X2) dan kepuasan konsumen (Y), Menganalisis data untuk mengetahui pengaruh dan hubungan antara variabel penelitian dengan teknik analisis, Mengubah data mentah menjadi bermakna (mentabulasi), dan Menarik kesimpulan dan saran.

\section{HASIL dan PEMBAHASAN}

Hasil pembahasan dalam penelitian dengan judul "Pengaruh Kualitas Produk dan Kuaitas Pelayanan Terhadap Kepuasan Konsumen di Sushi Den Bandung" adalah sebagai berikut:

Penulis melakukan penelitian dengan cara menyebarkan sejumlah kuesioner dengan beragam pertanyaan kepada responden mengenai kualitas produk dan kualitas pelayanan di Sushi Den Bandung. dimana yang menjadi responden dalam penelitian ini adalah konsumen restoran Sushi Den. Adapun pertanyaan yang menjadi ukuran dan diberikan kepada responden mengenai kualitas produk adalah tampilan produk makanan atau minuman, daya tarik peralatan makan yang digunakan, makanan dan minuman yang disajikan sesuai dengan selera konsumen, ukuran atau porsi makanan dan minuman sesuai, dan tingkat kematangan makanan. Sedangkan untuk pertanyaan tentang kualitas pelayanan ukuran yang ditanyakan adalah kerapihan penampilan pegawai, ketepatan pegawai dalam melayani konsumen, ketanggapan atau ketelitian pegawai pada saat melayani konsumen, keramahan dan kesopanan pegawai pada saat memberikan pelayanan, dan kepekaan atau kepedulian pegawai terhadap hal yang dibutuhkan konsumen. Berdasarkan perhitungan uji validitas dan uji reliabilitas dengan menggunakan pogram SPSS 22 for Windows, pernyataan yang diajukan kepada responden ini valid dan reliabel sehingga layak untuk diajukan.

Berdasarkan hasil pengolahan data yang dilakukan diperoleh hasil penelitian yaitu, konsumen Sushi Den belum mencapai kepuasan terhadap kualitas produk dan kualitas pelayanan yang telah diberikan. Hal ini disebabkan oleh tingginya nilai harapan konsumen dibandingkan dengan nilai kinerja atau hasil dari kualitas produk dan kualitas pelayanan yang dirasakan. Nilai terendah dalam kualitas produk terdapat pada daya tarik peralatan makan yang digunakan, yaitu sebesar 260, atau 17,543\% dari total kualitas produk dan untuk kualitas pelayanan yang memiliki nilai paling rendah adalah keramahan dan kesopanan pegawai pada saat memberikan pelayanan 
dan kepekaan atau kepedulian pegawai terhadap hal yang dibutuhkan konsumen, yaitu sebesar 268, atau 18,993\% dari total nilai kualitas pelayanan.

Hasil pengujian hipotesis menunjukan bahwa Kualitas Poduk dan Kualitas Pelayanan memiliki pengaruh signifikan terhadap kepuasan konsumen. Besarnya pengaruh kualitas produk dan kualitas pelayanan secara bersama-sama terhadap kepuasan konsumen restoran Sushi Den Bandung adalah sebesar 56,2\%, sedangkan sisanya dipengaruhi oleh faktor-faktor lain. Hasil koefisien regresi pada pengujian hipotesis menunjukan bahwa jika dilihat dari uji $\mathrm{F}$ dengan bantuan SPSS 22 for Windows diperoleh nilai $\mathrm{t}_{\text {hitung }}$ yang digunakan untuk mengukur tingkat signifikasi pengaruh variabel $\mathrm{X}_{1}$ dan $\mathrm{X}_{2}$ terhadap $\mathrm{Y}$. Rumus mencari $\mathrm{F}_{\text {tabel }}$ adalah dengan menggunakan $\mathrm{dk}$ (derajat kebebasan) $=\mathrm{N}-\mathrm{K}$. N disini berarti jumlah variabel dan $\mathrm{K}$ adalah variabel konstan (variabel $\mathrm{X}$ dan $\mathrm{Y}$ ), sehingga $\mathrm{dk}=100-3$, maka nilai $\mathrm{t}_{\text {tabel }}$ dengan $\mathrm{dk}=97$ dan dari hasil $\mathrm{t}_{\text {tabel }}$ 1.29034. Nilai $\mathrm{t}_{\text {hitung }}$ yang diperoleh adalah 11.780 .

Berdasarkan hasil dari uji t dapat dilihat bahwa untuk variabel kualitas produk dan kualitas pelayanan, $t_{\text {hitung }}>\mathrm{t}_{\text {tabel }}$ maka dapat disimpulkan bahwa Ho ditolak artinya kualitas produk dan kualitas pelayanan berpengaruh signifikan terhadap kepuasan pelanggan.

\section{SIMPULAN}

Berdasarkan hasil penelitian yang telah dilakukan untuk mengetahui pengaruh kualitas produk dan kualitas pelayanan terhadap kepuasan konsumen Sushi Den Bandung dapat ditarik suatu kesimpulan sebagai berikut: Kualitas Produk di Sushi Den Bandung masih kurang baik, hal tersebut tercermin dari hasil kuesioner dari pelanggan. Tingkat kematangan makanan adalah dimensi kualitas produk yang mempunyai nilai paling tinggi, sedangkan yang mempunyai nilai paling rendah adalah dari dimensi kualitas produk mengenai daya tarik peralatan makan yang digunakan. Kualitas Pelayanan di Sushi Den Bandung masih kurang baik, hal tersebut tercermin dari hasil kuesioner dari pelanggan. Ketepatan pegawai dalam melayani konsumen merupakan salah satu dimensi dari kualitas pelayanan yang memiliki nilai paling tinggi karena para pegawai yang berada di Sushi Den jarang sekali melakukan kesalahan seperti salah memberikan pesanan kepada konsumen, sedangkan nilai paling rendah adalah dimensi keramahan dan kesopanan pegawai pada saat memberikan pelayanan dan kepekaan atau kepedulian pegawai terhadap hal yang dibutuhkan konsumen. Konsumen restoran Sushi Den secara keseluruhan merasa tidak puas dengan kualitas produk dan kualitas pelayanan yang telah diberikan. Hal ini disebabkan oleh nilai hasil atau kinerja (perceived) yang dirasakan oleh konsumen restoran Sushi Den lebih rendah jika dibandingkan dengan harapan (expected) konsumen terhadap kualitas produk dan kualitas pelayanan yang ada disana. Kualitas produk dan kualitas pelayanan berpengaruh terhadap kepuasan konsumen Sushi Den Bandung yaitu sebesar 0,562 atau 56,2\%. 


\section{DAFTAR PUSTAKA}

Alma, Buchari. (2007). Manajemen Pemasaran dan Pemasaran Jasa. Bandung: $\quad$ CV. Alfabeta.

Arief, Muhtosim. (2007). Pemasaran Jasa dan Kualitas Pelayanan (Bagaimana Mengelola Kualitas Pelayanan agar Memuaskan Pelanggan). Malang: Bayumedia.

Arief, Abd Rachmat. (2005). Pengantar Ilmu Perhotelan dan Restoran. Yogyakarta: Graha Ilmu.

Bartono. (2005). Analisis Food Product Study Food Cost dan Pedoman Training. Yogyakarta: Andi.

Haryanti, Pitri. (2013). All About Japan (Panduan Lengkap\&Informatif tentang Jepang untuk belajar, bekerja dan berwisata). Yogyakarta: Andi.

Hurriyati, Ratih. (2010). Bauran Pemasaran dan Loyalitas Konsumen. Bandung: Alfabeta.

Iko, Saiko, d.k.k. (2003). Masakan Jepang. Proyek STPB.

Kotler, Philip. (2000). Manajemen Pemasaran. Jakarta: PT. Practicehall Indonesia.

Kotler, Philip and Armstrong, Gary. (2004). Prinsip-Prinsip Pemasaran Jasa, (jilid 1 edisi ke-8). Jakarta: Prenhallindo.

Kotler, Philip and Kevin Lane Keller. (2008). Manajemen Pemasaran (edisi

12 jilid 1). Erlangga.

Kotler, Philip and Kevin Lane Keller. (2010). Manajemen Pemasaran (edisi

13 jilid 1). Erlangga.

Lovelock, C., Wirtz, J and Mussry, J. (2010). Pemasaran Jasa (Manusia, Teknologi, Strategi. Perspektif Indonesia). Jakarta: Erlangga.

Marsum, WA. (2005) Restoran dan Segala Permasalahannya. Yogyakarta: Andi.

Payne, Adrian. (2000). The Essence of Service Marketing (Pemasaran Jasa). Yogyakarta: Andi.

Soekresno. (2000). Manajemen Food and Baverages Service Hotel. Jakarta: Gramedia.

Smith, Fiona. (2007). Sushi \& miso mudah saji (26 resep kilat). Jakarta: Erlangga.

Sugiyono. (2009). Statistika untuk Penelitian. Bandung: Erlangga.

Sugiyono. (2014). Statistika untuk Penelitian. Bandung: Erlangga.

Tjiptono, Fandy. (2005). Prinsip-Prinsip Total Quality Service. Yogyakarta: Andi.

Tjiptono, Fandy dan Chandra, Gregorius. (2007). Service, Quality, dan Satisfaction edisi 2. Yogyakarta: CV. Andi Offset.

Tri Ratnasari, Ririn dan H. Aksa, Mastuti. (2011). Manajemen Pemasaran

Jasa: Teori dan Kasus dalam Pemasaran Jasa.Bogor: Ghalia Indonesia.

Yeoti, Oka. A. (2010). Dasar-Dasar Pengertian Hospitaliti dan Pariwisata. Bandung: PT. Alumni. 
Alimin, Nurman. (2014). Upaya Meningkatkan Kepuasan Konsumen Melalui Kualitas Produk dan Kualitas Pelayanan di Katering Sarahfie. FPIPS UPI. Bandung, Tidak diterbitkan.

Nugraha, Reza Muhammad. (2012). Pengaruh Kualitas Produk, Harga dan Kualitas Pelayanan terhadap Kepuasan Konsumen pada Rumah Makan Iga Bakar di Bandung. FPIPS UPI. Bandung, Tidak diterbitkan.

Forsquare. (2015). Sushi Den. Restoran Sushi, Restoran Jepang, dan Rumah Mi [online], Tersedia: https://id.forsquare.com/v/sushiden/ 4b9b8c55f964a520a00e36e3.html [14 September 2015]

Munady, Prlm. (2014). Sektor Wisata Akan Tumbuh 12\% Pertahun [online], Tersedia: https:// www.pikiran-rakyat.com/wisata/ 2014/09/29/298909/sektorwisata-akantumbuh-12-tahun\# [14 September 2015]

Tripadvisor. (2015). Sushi Den [online], Tersedia: https:// www.tripadvisor.co.id/Restaurant_Review-g297704-d7347820-Reviews- Sushi_DenBandung_West-Java_Java.html [14 September 2015] 